\title{
Re-recognition of Age-dependent Reference Range for the Serum Creatinine Level in Teenagers - A Case of Slowly Progressive Tubulointerstitial Nephritis which Occurred in an Adolescent -
}

\author{
Hiroyuki Ono ${ }^{1}$, Kojiro Nagai ${ }^{1}$, Eriko Shibata ${ }^{1}$, Motokazu Matsuura ${ }^{1}$, Seiji Kishi ${ }^{1}$, \\ Taizo Inagaki ${ }^{1}$, Masanori Minato ${ }^{1}$, Sakiya Yoshimoto ${ }^{1}$, Sayo Ueda ${ }^{1}$, Fumiaki Obata ${ }^{1}$, \\ Kenji Nishimura ${ }^{1}$, Masanori Tamaki ${ }^{1}$, Fumi Kishi ${ }^{1}$, Taichi Murakami ${ }^{1}$, Hideharu Abe ${ }^{1}$, \\ Yukiko Kinoshita ${ }^{2}$, Maki Urushihara ${ }^{2}$, Shoji Kagami ${ }^{2}$ and Toshio Doi ${ }^{1}$
}

\begin{abstract}
:
For the first time, a 15-year-old boy was found to have a slight degree of proteinuria and microscopic hematuria during annual school urinalysis screening. His kidney function had already severely deteriorated. A kidney biopsy revealed tubulointerstitial nephritis (TIN) with diffuse inflammatory cell infiltration. His medical records showed his serum creatinine level to be $0.98 \mathrm{mg} / \mathrm{dL}$ two years ago, which was abnormally high considering his age. Although the etiology of slowly progressive TIN was unclear, glucocorticoid and immunosuppressant therapy improved his kidney function. This case report suggests that all doctors should recognize the reference range for the serum creatinine level in teenagers.
\end{abstract}

Key words: serum creatinine level, tubulointerstitial nephritis, $N$-acetyl-beta-D-glucosaminidase, $\beta_{2}$ microglobulin

(Intern Med 56: 2187-2193, 2017)

(DOI: 10.2169/internalmedicine.8599-16)

\section{Introduction}

Adolescents usually see general practitioners, not pediatricians. However, their reference ranges for some laboratory tests are different from those of adults. The serum creatinine level is one of the representative blood tests which are dependent on age, sex and muscle mass (Table 1) $(1,2)$. Generally speaking, the reference range for the serum creatinine level in adolescents is lower than that in adults.

Tubulointerstitial nephritis (TIN) leads to renal dysfunction and it is characterized by an infiltration of inflammatory cells in the renal interstitium. TIN is often induced by drugs and infections (3). TIN is sometimes one of the clinical manifestations in TIN and uveitis syndrome and sarcoidosis (4) or autoimmune disease such as Sjögren's syndrome,
IgG4-related disease and systemic lupus erythematosus $(5,6)$. Idiopathic forms of TIN have also been reported. TIN often occurs without any abnormal urinalysis findings, which makes it difficult to identify at an early stage (6). We herein describe the case of an adolescent whose severe renal dysfunction was found during an investigation of a small amount of proteinuria and microscopic hematuria. A renal biopsy revealed the cause of renal failure to be TIN, which had slowly been progressing based on his medical history.

\section{Case Report}

A 15-year-old boy was referred to our hospital because of a positive dipstick reading for proteinuria in the presence of microscopic hematuria, which was detected during school urinalysis screening. Laboratory tests revealed an elevation

${ }^{1}$ Department of Nephrology, Institute of Biomedical Sciences, Tokushima University Graduate School, Japan and ${ }^{2}$ Department of Pediatrics, Institute of Biomedical Sciences, Tokushima University Graduate School, Japan

Received: November 24, 2016; Accepted: December 26, 2016; Advance Publication by J-STAGE: August 1, 2017

Correspondence to Dr. Kojiro Nagai, knagai@tokushima-u.ac.jp 
Table 1. Reference Range of Serum Creatinine Level for 12 to 16 Year-old Adolescents (mg/dL).

\begin{tabular}{lllllll}
\hline Age & \multicolumn{2}{l}{ 2.5 percentile } & \multicolumn{2}{c}{50 percentile } & \multicolumn{2}{c}{97.5 percentile } \\
Sex & Male & Female & Male & Female & Male & Female \\
\hline 12 (years old) & 0.40 & 0.40 & 0.53 & 0.52 & 0.61 & 0.66 \\
13 & 0.42 & 0.41 & 0.59 & 0.53 & 0.80 & 0.59 \\
14 & 0.54 & 0.46 & 0.65 & 0.58 & 0.96 & 0.71 \\
15 & 0.48 & 0.47 & 0.68 & 0.56 & 0.93 & 0.72 \\
16 & 0.62 & 0.51 & 0.73 & 0.59 & 0.96 & 0.74 \\
\hline & & & \multicolumn{4}{c}{ (Quoted from reference 1) }
\end{tabular}

of his serum creatinine level to $2.73 \mathrm{mg} / \mathrm{dL}$, and therefore he was hospitalized for further examination.

His past school urinalysis tests had been within the normal range. He had no significant medical history, except for resection of a thyroglossal duct cyst two years before admission. The serum creatinine level of routine preoperative medical testing at that time was $0.98 \mathrm{mg} / \mathrm{dL}$. At that time, he was in a good physical condition with an average physique for his age. He did not take any drugs including supplements or Chinese herbal medicines. He did not have any symptoms, such as fever, skin rash, arthralgias, or peripheral eosinophilia suggestive of allergic reaction or infection.

On admission, he had no symptoms. His height was 162 $\mathrm{cm}$ and weight was $49.9 \mathrm{~kg}$. His blood pressure was 122/83 $\mathrm{mmHg}$, his pulse was $56 / \mathrm{min}$ with a regular rhythm, and his temperature was 36.6 degree centigrade. A physical examination showed no abnormalities in his heart, lungs, or abdomen. Purpura, skin rash, lymphadenopathy, arthralgia, myalgia, edema, and peripheral neuropathy were not found.

The laboratory data on admission are shown in Table 2 . The values of white blood cells and C-reactive protein were slightly increased without eosinophilia. The serum levels of blood urea nitrogen and creatinine were elevated without any abnormalities in electrolytes. Creatinine clearance was $26.8 \mathrm{~mL} / \mathrm{min}$. Other biochemical tests were nonspecific except: the $\operatorname{IgG}, \operatorname{IgG} 4, \operatorname{IgA}$ and $\operatorname{IgE}$ levels were slightly elevated and a urinalysis demonstrated $0.34 \mathrm{~g} / \mathrm{gCreatinine}$ of proteinuria, microscopic hematuria, high $N$-acetyl-beta-Dglucosaminidase (NAG) and $\beta_{2}$ microglobulin $\left(\beta_{2} \mathrm{MG}\right)$, suggesting tubulointerstitial injury in the kidneys. In order to rule out the specific diseases that cause tubulointerstitial nephritis, serological tests including an autoantibody analysis were performed which resulted in negative studies for angiotensinogen converting enzyme, anti double-stranded DNA, Sm, SS-A, SS-B, myeloperoxidase anti-neutrophil cytoplasmic antibody (MPO-ANCA), proteinase (PR)3-ANCA, and glomerular basement membrane antibodies.

The chest radiography and electrocardiogram findings were normal. An abdominal ultrasound examination showed both kidneys to be slightly smaller than usual (Right kidney: $90 \times 41 \mathrm{~mm}$, Left kidney: $92 \times 44 \mathrm{~mm}$ ), and their margins were irregular, and cortexes were bright, indicating a chronic impairment of the kidney function. Computed tomography, magnetic resonance imaging and gallium scintigraphy showed no abnormalities, except for the kidney morphology described above. The existence of uveitis was ruled out based on an ophthalmological examination.

After admission, the first renal biopsy was performed. Six of nineteen glomeruli were globally sclerotic. The rest of the glomeruli had no particular abnormality. Of note, there was diffuse interstitial cell infiltration with interstitial fibrosis and tubular atrophy (Fig. 1). Almost $80 \%$ of the tubulointerstitial area was damaged especially by cell infiltration which mainly consisted of T and B lymphocytes. Some of the infiltrative cells were IgG4 positive (4-5/high power field), which did not meet the criteria of IgG4 related kidney disease (data not shown). Eosinophils were barely detectable by Hematoxylin and Eosin stained biopsy samples (data not shown). The immunofluorescence results were negative for IgG, IgA, IgM, C3, C4, C1q, and Fib. Thus, renal failure was considered to have been caused by TIN. The patient's clinical course is shown in Fig. 2. Sixty $\mathrm{mg} /$ day of oral prednisolone treatment was started. His renal function gradually improved, and seven weeks after the initiation of prednisolone, his serum creatinine level decreased to 1.49 $\mathrm{mg} / \mathrm{dL}$. Then, a second renal biopsy was performed to evaluate the efficacy of corticosteroid therapy. Light microscopy showed a decrease of inflammatory cell infiltration and an improvement of tubular atrophy (Fig. 3), thus indicating that the corticosteroid therapy was effective. Around 20 to $30 \%$ of tubulointerstitial area was affected, especially by fibrosis. He was then administered methylprednisolone pulse (MP) therapy (a single intravenous drip infusion of $500 \mathrm{mg}$ / day of methylprednisolone for three consecutive days) and thereafter showed a further improvement. After MP therapy, prednisolone was reduced to $20 \mathrm{mg} /$ day, and $100 \mathrm{mg} /$ day of mizoribine was added. No significant complications associated with prednisolone and mizoribine occurred except for a slight increase in his blood pressure and uric acid levels. He was discharged from our hospital 10 weeks after admission with a creatinine level of $1.47 \mathrm{mg} / \mathrm{dL}$ (creatinine clearance: $49.7 \mathrm{~mL} / \mathrm{min}$ ). One year after discharge, he was taking $5 \mathrm{mg}$ of prednisolone and $100 \mathrm{mg} /$ day of mizoribine. In addition, his serum creatinine level was stable at around $1.5 \mathrm{mg} / \mathrm{dL}$.

\section{Discussion}

The definition of chronic kidney disease (CKD) was pro- 
Table 2. Laboratory Findings on Admission.

\begin{tabular}{|c|c|c|c|c|c|}
\hline Hematology & & Biochemis & & Serology & \\
\hline WBC & $10,500 / \mu \mathrm{L}$ & $\mathrm{TP}$ & $8.8 \mathrm{~g} / \mathrm{dL}$ & $\operatorname{IgG}$ & $1,793 \mathrm{mg} / \mathrm{dL}$ \\
\hline Neutrophils & $77.8 \%$ & Alb & $4.5 \mathrm{~g} / \mathrm{dL}$ & IgG4 & $150 \mathrm{mg} / \mathrm{dL}$ \\
\hline Lymphocytes & $14.5 \%$ & BUN & $22 \mathrm{mg} / \mathrm{dL}$ & $\operatorname{IgA}$ & $528 \mathrm{mg} / \mathrm{dL}$ \\
\hline Eosinophils & $2.0 \%$ & $\mathrm{Cr}$ & $2.73 \mathrm{mg} / \mathrm{dL}$ & $\operatorname{IgM}$ & $174 \mathrm{mg} / \mathrm{dL}$ \\
\hline $\mathrm{Hb}$ & $13.4 \mathrm{~g} / \mathrm{dL}$ & UA & $5.8 \mathrm{mg} / \mathrm{dL}$ & $\operatorname{IgE}$ & $239.7 \mathrm{mg} / \mathrm{dL}$ \\
\hline \multirow[t]{3}{*}{ Plt } & $45.6 \times 10^{4} / \mu \mathrm{L}$ & $\mathrm{Na}$ & $139 \mathrm{mEq} / \mathrm{L}$ & & \\
\hline & & K & $4.2 \mathrm{mEq} / \mathrm{L}$ & $\mathrm{C} 3$ & $128 \mathrm{mg} / \mathrm{dL}$ \\
\hline & & $\mathrm{Cl}$ & $104 \mathrm{mEq} / \mathrm{L}$ & $\mathrm{C} 4$ & $34 \mathrm{mg} / \mathrm{dL}$ \\
\hline Urinalysis & & $\mathrm{Ca}$ & $9.9 \mathrm{mg} / \mathrm{dL}$ & CH50 & $56 \mathrm{U} / \mathrm{mL}$ \\
\hline $\mathrm{pH}$ & 7.0 & $\mathrm{P}$ & $3.4 \mathrm{mg} / \mathrm{dL}$ & & \\
\hline $\mathrm{RBC}$ & 10-19/HPF & $\mathrm{Mg}$ & $2.2 \mathrm{mg} / \mathrm{dL}$ & ASO & $<50 \mathrm{IU} / \mathrm{mL}$ \\
\hline WBC & 10-19/HPF & T-Bil & $0.4 \mathrm{mg} / \mathrm{dL}$ & $\mathrm{RF}$ & $<10 \mathrm{IU} / \mathrm{mL}$ \\
\hline Hyaline Cast & $0-1 / \mathrm{LPF}$ & AST & $16 \mathrm{U} / \mathrm{L}$ & ANA & $\times 40$ \\
\hline Granular Cast & $0-1 / \mathrm{LPF}$ & ALT & $13 \mathrm{U} / \mathrm{L}$ & Anti-ds-DNA Ab & $(-)$ \\
\hline$\beta_{2}$ microglobulin & $58,380 \mu \mathrm{g} / \mathrm{L}$ & LDH & $113 \mathrm{U} / \mathrm{L}$ & Anti-Sm Ab & $(-)$ \\
\hline NAG & $12.3 \mathrm{U} / \mathrm{L}$ & CK & $57 \mathrm{U} / \mathrm{L}$ & Anti-SS-A Ab & $(-)$ \\
\hline \multirow[t]{2}{*}{ U-pro/U-Cr } & $0.34 \mathrm{~g} / \mathrm{gCr}$ & T-Cho & $149 \mathrm{mg} / \mathrm{dL}$ & Anti-SS-B Ab & $(-)$ \\
\hline & & TG & $180 \mathrm{mg} / \mathrm{dL}$ & MPO-ANCA & $(-)$ \\
\hline \multirow[t]{5}{*}{ Creatinine clearance } & $26.8 \mathrm{~mL} / \mathrm{min}$ & HDL-C & $30 \mathrm{mg} / \mathrm{dL}$ & PR3-ANCA & $(-)$ \\
\hline & & CRP & $0.75 \mathrm{mg} / \mathrm{dL}$ & Anti-GBM Ab & $(-)$ \\
\hline & & & & HBs-Ag & $(-)$ \\
\hline & & & & $\mathrm{HCV}-\mathrm{Ab}$ & $(-)$ \\
\hline & & & & ACE & $12.5 \mathrm{IU} / \mathrm{mL}$ \\
\hline
\end{tabular}

WBC: white blood cell, Hb: hemoglobin, Plt: platelet, RBC: red blood cell, NAG: $N$-acetyl-beta-D-glucosaminidase, U-pro/U-Cr: urinary protein/urinary creatinine,TP: total protein, Alb: albumin, BUN: blood urea nitrogen, Cr: creatinine, UA: uric acid, Na: sodium, K: potassium, Cl: cloride, Ca: calcium, P: phosphate, Mg: magnesium, T-Bil: total bilirubin, AST: L-aspartate aminotransferase, ALT: alanine aminotransferase, LDH: lactate dehydrogenase, CK: creatine kinase, T-chol: total cholesterol, TG: triglyceride, HDL-C: high density lipoprotein cholesterol, CRP: C-reactive protein, ASO: anti-streptolysin O, RF: rheumatoid factor, ANA: anti-nuclear antibody, ds-DNA: double stranded DNA, $\mathrm{Ab}$ : antibody, MPO: myeloperoxidase, ANCA: anti-neutrophil cytoplasmic antibody, PR3: proteinase 3, GBM: glomerular basement membrane, Ag: antigen, ACE: angiotensin converting enzyme

posed in Kidney Disease Outcomes Quality Initiative (K/ DOQI) clinical practice guidelines for CKD by the National Kidney Foundation in 2002 (7). The glomerular filtration rate (GFR) estimating equations for Japanese populations are a robust reflection of the response to the CKD guidelines in Japan (8). It is therefore considered important for both nephrology professionals and medical practitioners to understand the clinical relevance of CKD. However, the established equations have only been proposed for people 18 years old or older. Adolescents can therefore be a pitfall for doctors, because they are usually healthy and the onset of kidney diseases is rarely predicted. Therefore, not many doctors recognize the reference range for serum creatinine in adolescents. In this case, we want to emphasize the importance of an early detection of renal impairment. $0.98 \mathrm{mg} / \mathrm{dL}$ of serum creatinine level two years before admission was abnormal considering his age. The serum creatinine level can be higher if the body muscle is large. However, his height and weight were normal. Probably, the abnormal creatinine level was overlooked because the result was within the reference range for adults. Thus, the reference range does not always mean the normal range. The value may be due to a technical or sample error, but it would have been preferable to re-evaluate this patient to rule out any hidden kidney disease. If that have been done, then this patient could have been treated earlier, and his kidney function would have been better preserved. Notably, serum creatinine-based and cystatin C-based estimated GFR equations in Japanese children and adolescents were established by comparison with renal inulin clearance (Table 3) $(9,10)$. These equations can therefore help to identify hidden kidney diseases.

We have to know that TIN can represent a frequent cause of kidney injury with either no or only inconspicuous symptoms. Therefore, the presence of specific extrarenal symptoms, such as fever, skin rash, arthralgias, and peripheral eosinophilia, plays an important role in making a timely clinical diagnosis (5). In addition, TIN does not always manifest with urinalysis abnormalities, which thus prevents an early detection of kidney disease. Tubulointerstitial injury markers such as NAG and $\beta_{2} \mathrm{MG}$ are the commercially available markers for detecting an early stage of TIN, although these markers are not evaluated routinely by medical practitioners. 
(A)
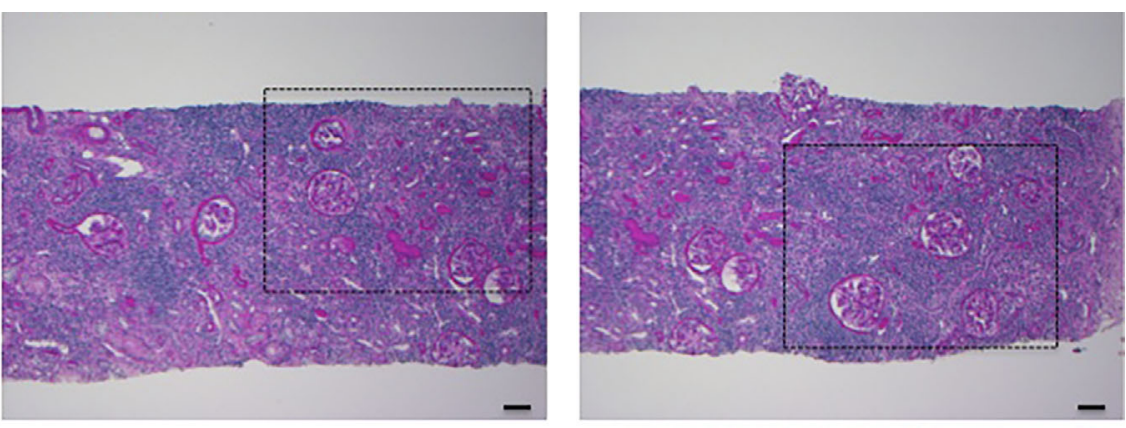

(B)
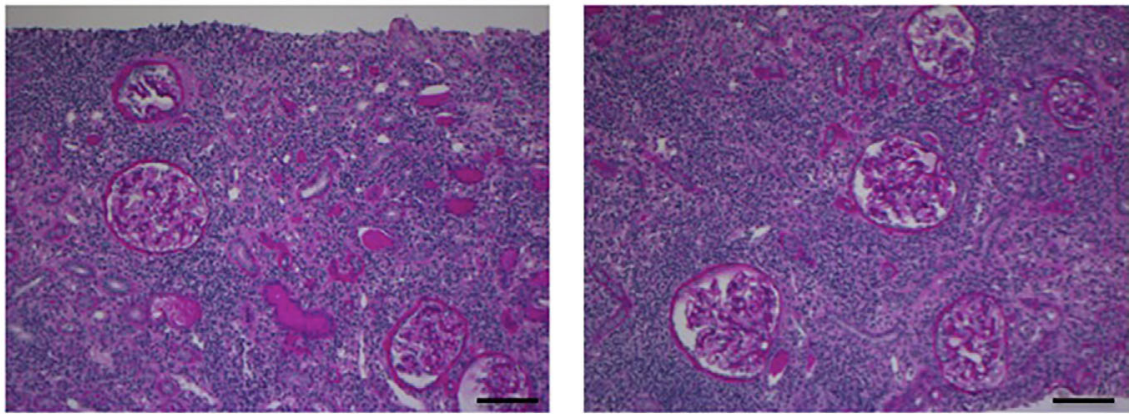

(C) $\mathrm{CD} 3$

(D) $\mathrm{CD} 20$
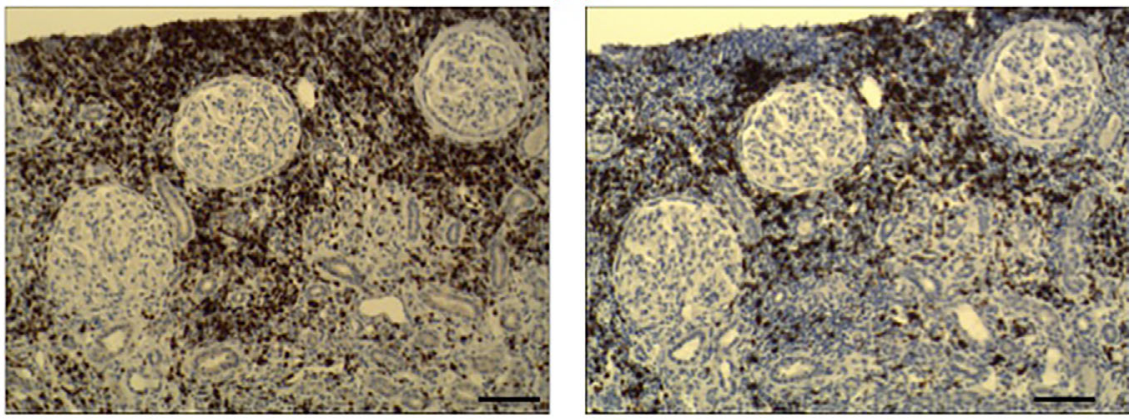

(E) CD68

(F) CD138
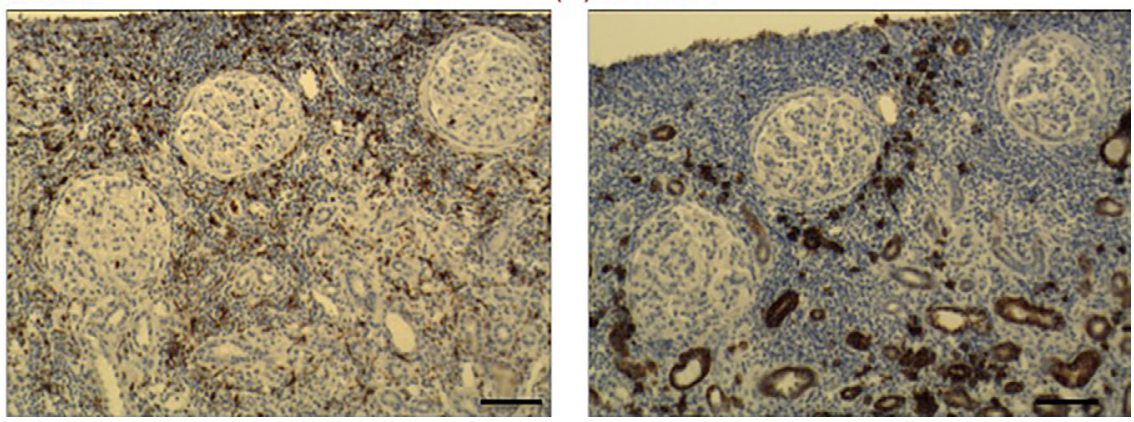

Figure 1. Representative pictures obtained from the first biopsy. (A, B) Diffuse interstitial cell infiltration was observed with interstitial fibrosis and tubular atrophy. The rectangle area in (A) was magnified to (B). (C, D, E, F) Cell marker staining. The antibodies against CD3 (2GV6) (T lymphocyte marker) and CD20 (L26) (B lymphocyte marker) were obtained from Ventana Medical Systems (Tucson, USA). The antibodies against CD68 (PG-M1) (Monocyte marker) and CD138 (MI15) (Plasma cell marker) were purchased from Dako Japan (Tokyo, Japan). Anti-CD138 antibody showed nonspecific staining in the tubule cells. Scale bars represent $100 \mu \mathrm{m}$.

The causes of acute TIN included drugs (70\%), autoimmune diseases (20\%), and infections (4\%) (6). Therefore, idiopathic cases are relatively rare. In our case, the patient was asymptomatic and had no specific physical manifestations to suggest TIN. He did not take any drugs and had no history of recent infections and no serological abnormalities indicating autoimmune diseases. Moreover, sarcoidosis and
IgG4-related kidney disease was excluded by pathological investigations. Thus, this case was diagnosed as idiopathic TIN. Although the optimal treatment for TIN has not yet been established, the most important aspect of therapy of TIN is the removal of any potential causative agents. It has been reported that the cessation of responsible agents or treatment of the underlying infection may lead to an im- 


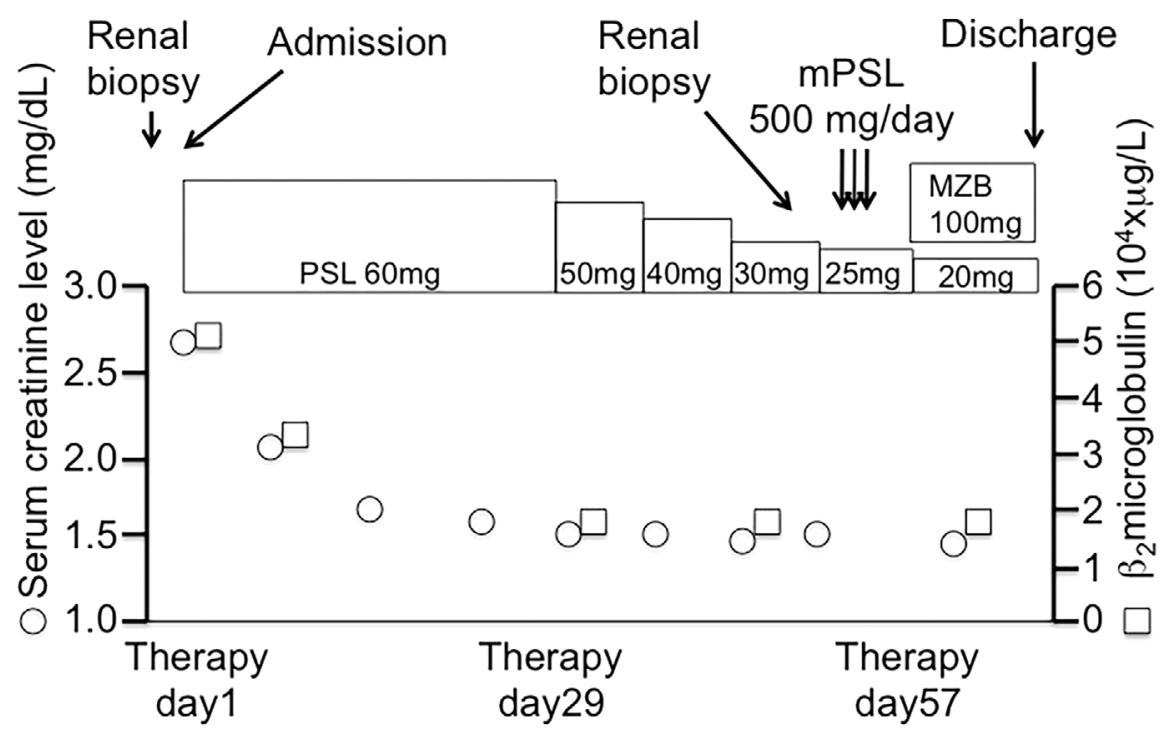

Figure 2. Clinical course of the patient. Coritcosteroid therapy was effective for the treatment of slowly progressive tubulointerstitial nephritis. PSL: prednisolone, mPSL: methylprednisolone, MZB: mizoribine
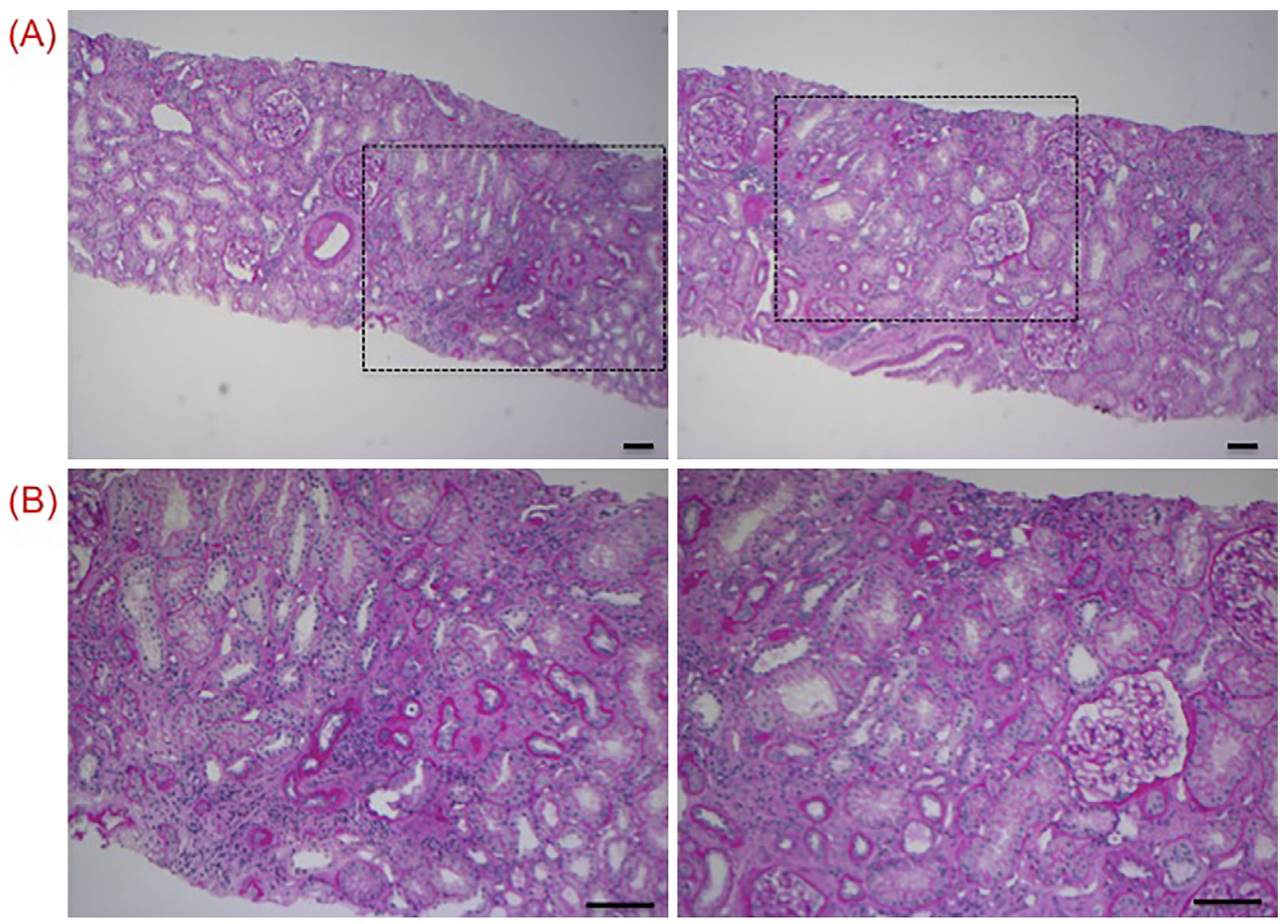

Figure 3. Representative pictures obtained from the second biopsy. (A, B) Corticosteroid therapy decreased inflammatory cell infiltration and improved tubular atrophy in the kidneys. Rectangle area in (A) was magnified to (B). Scale bars represent $100 \mu \mathrm{m}$.

provement of the renal function (11). However, a limited number of studies have reported on the treatment of idiopathic TIN. In our case, both kidneys were atrophic in abdominal ultrasound examinations. Gallium scintigraphy did not show an abnormal uptake in either kidney, probably because the patient's disease was not during the acute phase, though gallium scintigraphy lacks sensitivity and specificity to identify acute interstitial nephritis $(12,13)$. However, dif- fuse interstitial cell infiltration remained, while more than $30 \%$ of the total obtained glomeruli were globally screlotic in the first kidney biopsy sample, suggesting not chronic, not acute but slowly progressive TIN. Therefore, we expected that immunosuppressive therapy would be still effective. Glucocorticoid therapy appears to have a positive effect in patients with TIN, especially when treatment is initiated early in the course of the disease $(12,14)$. Immunosuppres- 
Table 3. Proposed Equations in Japanese Children and Adolescents to Detect the Early Phase of Kidney Diseases.

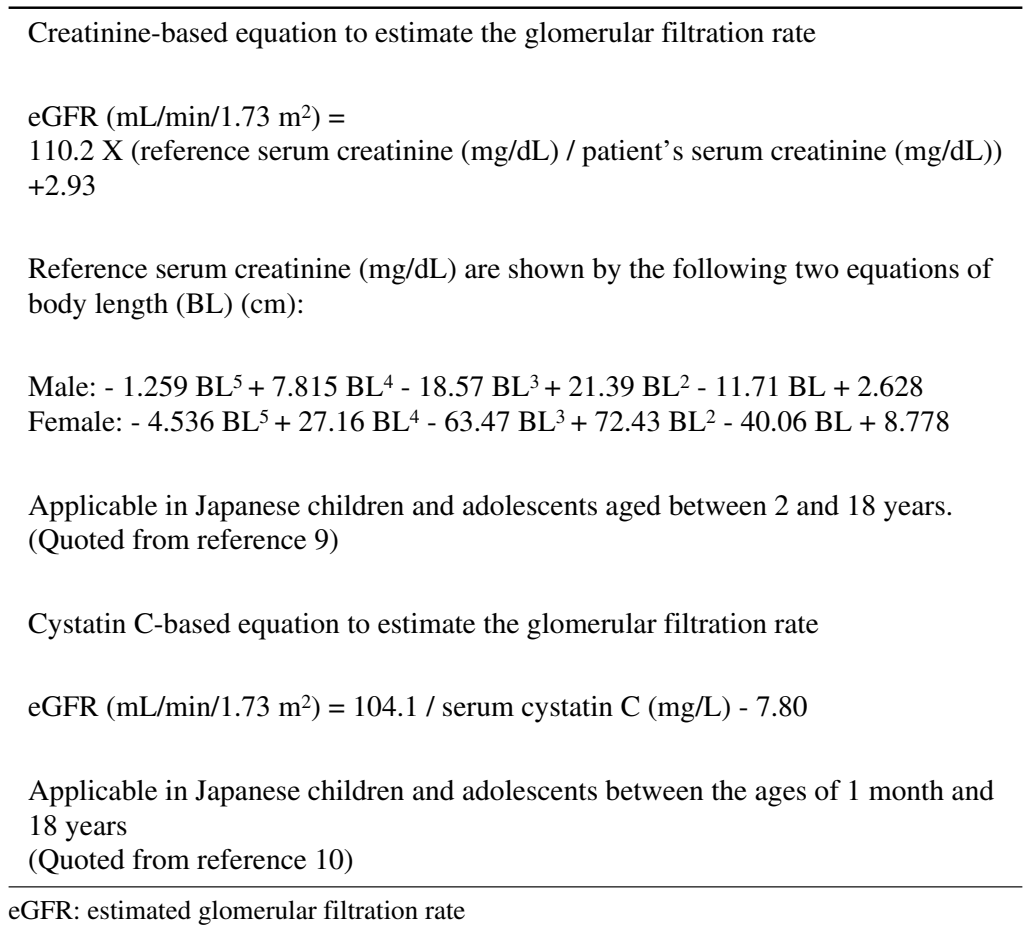

sant drugs were suggested to be a therapeutic option considering the pathogenesis of interstitial nephritis (15) and they have been used effectively in several case reports $(16,17)$. Among routinely used immunosuppressant drugs to treat kidney diseases, such as cyclophosphamide, cyclosporine A and mizoribine, cyclophosphamide metabolites alkylate DNA bases and preferentially suppress immune responses mediated by B lymphocytes. Cyclosporine A inhibits the phosphatase activity of calcineurin, thereby suppressing the production of interleukin-2 (IL-2) and other cytokines by $\mathrm{T}$ lymphocytes (18), while mizoribine is an antimetabolite that exerts its immunosuppressant effect by inhibiting both $\mathrm{T}$ and B lymphocyte proliferation (19). As shown in Fig. 1, infiltrating cells in the tubulointerstitial area consists mainly of both $\mathrm{T}$ and $\mathrm{B}$ lymphocytes. We wanted to reduce the young patient's disease activity and corticosteroid use as much as possible. Therefore, mizoribine was administered because its suppressive effects on both $\mathrm{T}$ and $\mathrm{B}$ lymphocytes and its relative lack of toxicity. At first, we used $150 \mathrm{mg} /$ day of mizoribine. However, it caused hyperuricemia as a side effect. As a result, we decreased the dosage of mizoribine to 100 mg/day.

Finally, corticosteroid and mizoribine therapy was able to moderately decrease the serum creatinine level. There are no definite criteria to discontinue corticosteroid treatment. We might perform a kidney biopsy again to confirm the lack of infiltrating cells in the interstitial area which would thus allow us to stop the administration of corticosteroids, though a relapse of interstitial nephritis could still occur even if the previous treatment had been sufficient.

In summary, this is a case of idiopathic slowly progres- sive TIN, which was found through school urinalysis screening. We need to recognize the reference range for the serum creatinine level, serum creatinine-based and cystatin C-based estimated GFR equations in teenagers and the evaluation of not only routine urinalysis, but also tubulointerstitial injury markers such as NAG and $\beta_{2} \mathrm{MG}$ are recommended to detect the presence of early stage kidney diseases including TIN.

The authors state that they have no Conflict of Interest (COI).

\section{Acknowledgement}

We thank Yoko Okazawa, Akiyo Muramoto (Tokushima University) for their valuable clinical assistance.

\section{References}

1. Uemura O, Honda M, Matsuyama T, et al. Age, gender, and body length effects on reference serum creatinine levels determined by an enzymatic method in Japanese children: a multicenter study. Clin Exp Nephrol 15: 694-699, 2011.

2. Ishikura $\mathrm{K}$, Uemura $\mathrm{O}$, Ito $\mathrm{S}$, et al. Pre-dialysis chronic kidney disease in children: results of a nationwide survey in Japan. Nephrol Dial Transplant 28: 2345-2355, 2013.

3. Schwarz A, Krause PH, Kunzendorf U, Keller F, Distler A. The outcome of acute interstitial nephritis: risk factors for the transition from acute to chronic interstitial nephritis. Clin Nephrol 54: 179-190, 2000.

4. Baker RJ, Pusey CD. The changing profile of acute tubulointerstitial nephritis. Nephrol Dial Transplant 19: 8-11, 2004.

5. Praga M, González E. Acute interstitial nephritis. Kidney Int 2010 77: 956-961, 2010.

6. Muriithi AK, Leung N, Valeri AM, et al. Biopsy-proven acute interstitial nephritis, 1993-2011: a case series. Am J Kidney Dis 64: 558-566, 2014 
7. National Kidney Foundation. K/DOQI clinical practice guidelines for chronic kidney disease: evaluation, classification, and stratification. Am J Kidney Dis 39 (2 Suppl 1): S1-S266, 2002.

8. Mastuo S, Imai E, Horio M, et al. Revised equations for estimating glomerular filtration rate (GFR) from serum creatinine in Japan. Am J Kidney Dis 53: 982-992, 2009.

9. Uemura O, Nagai T, Ishikura $\mathrm{K}$, et al. Creatinine-based equation to estimate the glomerular filtration rate in Japanese children and adolescents with chronic kidney disease. Clin Exp Nephrol 18: 626-633, 2014.

10. Uemura O, Nagai T, Ishikura $K$, et al. Cystatin C-based equation for estimating glomerular filtration rate in Japanese children and adolescents. Clin Exp Nephrol 18: 718-725, 2014.

11. Buysen JG, Houthoff HJ, Krediet RT, Arisz L. Acute interstitial nephritis: a clinical and morphological study in 27 patients. Nephrol Dial Transplant 5: 94-99, 1990.

12. Perazella MA, Markowitz GS. Drug-induce acute interstitial nephritis. Nat Rev Nephrol 6: 461-470, 2010.

13. Rossert J. Drug-induced acute interstitial nephritis. Kidney Int 60 804-817, 2001.

14. Raghavan R, Eknoyan G. Acute interstitial nephritis - a reappraisal and update. Clin Nephrol 82: 149-162, 2014.
15. Neilson EG. Pathogenesis and therapy of interstitial nephritis. Kidney Int 35: 1257-1270, 1989.

16. Lee JW, Kim HJ, Sung SH, Lee SJ. A case of tubulointerstitial nephritis and uveitis syndrome with severe immunologic dysregulation. Pediatr Nephrol 20: 1805-1808, 2005.

17. Büscher R, Vij O, Hudde T, Hoyer PF, Vester U. Pseudotumor cerebri following cyclosporine A treatment in a boy with tubulointerstitial nephritis associated with uveitis. Pediatr Nephrol 19: 558-560, 2004.

18. Allison AC. Immunosuppressive drugs: the first 50 years and a glance forward. Immunopharmacology 47: 63-83, 2000.

19. Yoshikawa $N$, Nakanishi $K$, Ishikura $K$, Hataya $H$, Iijima $K$, Honda M; Japanese Pediatric IgA Nephropathy Treatment Study Group. Combination therapy with mizoribine for severe childhood IgA nephropathy: a pilot study. Pediatr Nephrol 23: 757-763, 2008.

The Internal Medicine is an Open Access article distributed under the Creative Commons Attribution-NonCommercial-NoDerivatives 4.0 International License. To view the details of this license, please visit (https://creativecommons.org/licenses/ by-nc-nd/4.0/).

(C) 2017 The Japanese Society of Internal Medicine Intern Med 56: 2187-2193, 2017 